www.jmscr.igmpublication.org

Impact Factor (SJIF): 6.379

Index Copernicus Value: 79.54

ISSN (e)-2347-176x ISSN (p) 2455-0450

crossrefDOI: https://dx.doi.org/10.18535/jmscr/v6i8.190

Journal Of Medical Science And Clinical Research

IGM Publication

An Official Publication of IGM Publication

\title{
Original Research Article \\ Evaluation of Lesions of Lymph Node in a Rural Teaching Hospital in one year (2017)
}

Authors

\section{Dhanalakshmi ${ }^{1}$, S. Venkateswaran ${ }^{2}$, B. Krishnaswamy ${ }^{3 *}$}

${ }^{1}$ Reader in Pathology, Department of Pathology, Rajah Muthiah Medical College and Hospital, Annamalai University, Annamalai nagar, Chidambaram- 608002.

${ }^{2}$ Post graduate in Pathology, Department of Pathology, Rajah Muthiah Medical College and Hospital, Annamalai University, Annamalai nagar, Chidambaram- 608002

${ }^{3}$ Professor in Pathology, Department of Pathology, Rajah Muthiah Medical College and Hospital,

Annamalai University, Annamalai nagar, Chidambaram- 608002

*Corresponding Author

B. Krishnaswamy

Professor in Pathology, Department of Pathology, Rajah Muthiah Medical College and Hospital, Annamalai University, Annamalai nagar, Chidambaram- 608002

Email: drbkrishnaswamy2014@gmail.com, Mob: 9444161540

\begin{abstract}
Introduction: As a part of peripheral or secondary lymphoid organs, lymph nodes are a vital part of immune system. Their increase in size is referred to in a huge spectrum of diseases, inclusive of infections and malignancy, they may be a common finding in scientific practice. Therefore, peripheral lymph adenopathy is commonplace in all age groups and control of instances relies upon on lymph node pathology, which may be studied through collecting material via fine-needle aspiration or excision biopsy.

Objectives: Evaluation of the cytomorphological features and prevalence of various lymph node diseases on fine-needle aspiration cytology (FNAC) and to research the usefulness and diagnostic importance of FNAC in lymph node lesions.

Materials and Methods: Evaluation of one hundred cases with lymph node lesions at Department of Pathology in Rajah Muthiah medical college.

Results: Reactive lymphoid lesions comprised (33.69\%) of cases, next to it was tubercular lymphadenitis, metastatic malignancies, acute suppurative lymphadenitis, and lymphomas, respectively.

Conclusion: Reactive lymphoid and tubercular lesions have been the most significant lesion of the lymph node swellings presentations. FNAC is a simple, safe, reliable, and cost-effective technique in early detection of lymph node lesions, which has been validated once more on this evaluation.
\end{abstract}

\section{Introduction}

Lymph nodes are an important part of the immune system and are routine presentation in the medical cases. The lymphoid system grows swiftly in early life and achieves two times the adult size in early childhood. The lymph node starts regressing all through mid-formative years, it does not attain its fixed size till 20-25 years. Lymph nodes are place 
for prepared collections of lymphoreticular tissue and are red grey bean encapsulated organs. They are placed at anatomically regular fashion alongside the route of lymphatic vessels. The major sites of distribution are cervical, axillary, mediastinal, retroperitoneal, iliac, and inguinal regions.

Dating back in history, Kun in 1847 had carried out the pioneering act of first time reporting using aspiration biopsy. Since then fine-needle aspiration cytology (FNAC) has been a simple, secure, dependable, and less expensive method of setting up the diagnosis of lesions and masses in various location and organs and is the most handy bedside diagnostic aid ${ }^{1-5}$. As a minimally invasive technique, it additionally facilitates in early path of appropriate investigations. Drawbacks of FNAC also exist like sampling errors in form of wrong technique, micro metastasis, benign epithelial inclusions, partial lymph node involvement with the aid of lesion and a completely small lymph node where sampling is tough, also an excessive prevalence of fake outcomes, specifically false negative inside the case of lymphomas and the handicaps like evaluation of lymph node structure, which is not possible on cytological evaluation. ${ }^{[5-7]}$

\section{Materials and Methods}

This evaluation was undertaken in Department of Pathology at Rajah Muthiah Medical College to study the various cytomorphological characteristics of neoplastic and non-neoplastic lesions of lymph nodes through FNAC in patients presenting with lymphadenopathy and to determine the prevalence of numerous lymph node lesions among them. The evaluation carried was out over aperiod of one year, and 100 cases of lymphadenopathy of assorted etiologies had been considered. All patients having lymphadenopathy were assessed in the evaluation, and they were grouped with correlation to the dimensions of lymphadenopathy into following categories:

1. $<1 \mathrm{~cm}$.

2. $1-2 \mathrm{~cm}$.

\section{3. $>2 \mathrm{~cm}$.}

Study groups have been subjected to standard FNA procedure after taking consent from the affected person or relative. After studying all the case details, the smears have been observed with the microscope. Based on the cellularity, the smears were categorized as of high, mild, and low cellularity. The smears, which have been hemorrhagic or with scanty cellularity to the level where diagnosis could not be made were categorized as insufficient for opinion.

\section{Results}

100 aspirates were taken for evaluation out of which 78 were male patients and 22 female patients. The age of the cases varied from one year to eighty-two years with an average age of fortyone years. The maximum incidences of cases had been seen within the age group of 20-30 years. A mild male preponderance with a male to female ratio of $1.17: 1$ became cited. Lymph nodes of various sizes have been subjected to FNAC. The smallest lymph node measured $0.5 \mathrm{~cm}$ and the largest measured $4 \mathrm{~cm}$. Most of the lymph nodes (seventy-eight) ranged in size among one and two centimeters. The most common sites of lymph nodes aspirated had been in a decreasing order cervical $(50.80 \%)$, submandibular and supraclavicular $(12.30 \%)$ each, axillary, and inguinal $(10 \%)$ each and generalized which were five percent. A cytological diagnosis changed into made in ninety-two instances at the same time as no opinion become feasible in eight instances due to the inadequacy of the aspirates. Of the 92 cases, 31 cases $(33.69 \%)$ were recognized as reactive hyperplasia, after that 27 cases $(28.88 \%)$ of tubercular lymphadenitis (Figure 3-5)was observed and 16 cases of metastatic malignancy (17.65\%) (Figure 6-8), 6 instances $(6.42 \%)$ of acute suppurative lymphadenitis (Figure 1 and 2) and total of cases of non-Hodgkin's lymphoma (NHL) $(2.14 \%)$ and a single case of Hodgkin's lymphoma.

The majority of instances recorded have been reactive hyperplasia $(33.69 \%)$ wherein $58.7 \%$ 
have been from the cervical lymph nodes. A detailed case details and local examination of the affected person discovered perpetually a septic or infective foci in the head and neck place like that of otitis media, tonsillitis, dental caries, and scalp lesions in maximum of the cases. The smears revealed high yield, the polymorphic population of lymphocytes and tingible body macrophages, which might be the 3 important characteristics of reactive follicular hyperplasia. The polymorphic population accommodates of lymphocytes at exclusive phases of maturation, monocytoid B cells and plasma cells. The lymphoid cells consisted of small mature lymphocytes, small and huge cleaved cells and noncleaved cells and immunoblasts. The ratio is estimated to be $4: 1$ for small to large cells.

Two cases of dermatopathic lymphadenitis were recorded inside the study. The smears confirmed predominantly pale histiocytes like cells with generally folded nuclei among small lymphocytes and macrophages containing pigment.

In both the instances, sufferers had clinically supplied with psoriasis and generalized dermatitis.

A slight male preponderance was observed in the study. most range of instances recorded within the cervical lymph nodes observed by way of supraclavicular. Maximum instances of metastatic deposits inside the study were those of squamous cell carcinoma (fifty-one \%), accompanied by way of adenocarcinomas (30\%), small cellular carcinoma of lungs (three \%), malignant cancer (6\%), anaplastic huge cell carcinoma (6\%), carcinoma deposits of breast and undifferentiated metastatic deposits (4\%).

A total of 6 cases $(6.4 \%)$ of acute suppurative lymphadenitis have been recorded in these cases, maximum of them in the axillary group of lymph nodes. The smears revealed both well-preserved and degenerated neutrophils and cellular debris (Figures 1 and 2). In the initial phase if the lymph node is aspirated then amixture of lymphocytes and neutrophils may be visible. With the treatment commenced the aspirates show a varied population of cells comprising of polymorphs, lymphocytes, plasma cells and histiocytes along with cellular debris. This pattern of arrangement of inflammatory exudates in suppurative lymphadenitis become seen in cases in our evaluation in patients who had underwent FNAC after intake of the antibiotics

There had been a total of 3 patients $(2.6 \%)$ of lymphomas, amongst which one case was of Hodgkin's lymphoma, and the rest of the 4 have been NHL. The single case of Hodgkin's disorder was an aged male and confirmed Reed- Sternberg cells and Hodgkin cells towards a background of reactive components such as eosinophils, plasma cells and benign histiocytes. Hence, the confidence of diagnosis increased, and the case was further grouped as mixed cellularity type which was ascertained with histopathological examination. The four cases of NHL have been all adult males and presented with inguinal, submandibular, and supraclavicular lymphadenopathy. All the cases had been further confirmed on histopathology.

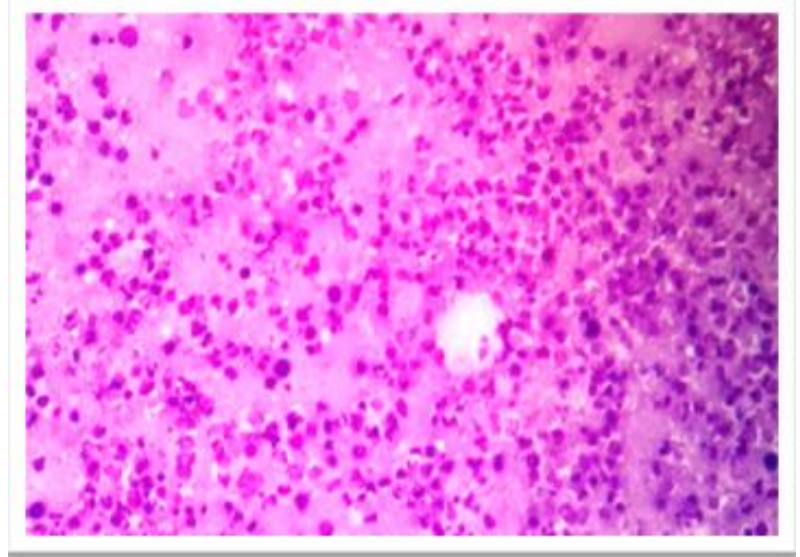

Figure 1: Acute suppurative lymphadenitis

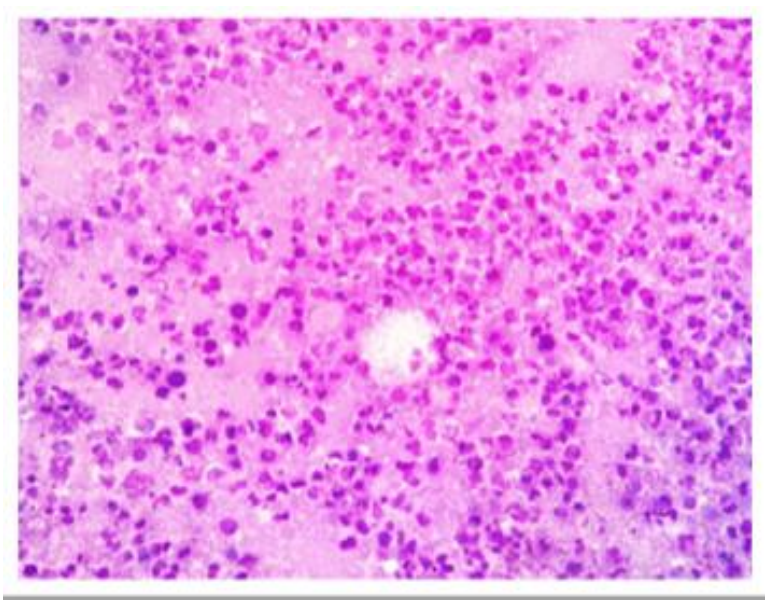

Figure 2: Acute suppurative lymphadenitis 


\section{JMSCR Vol||06||Issue||08||Page 1149-1156||August}

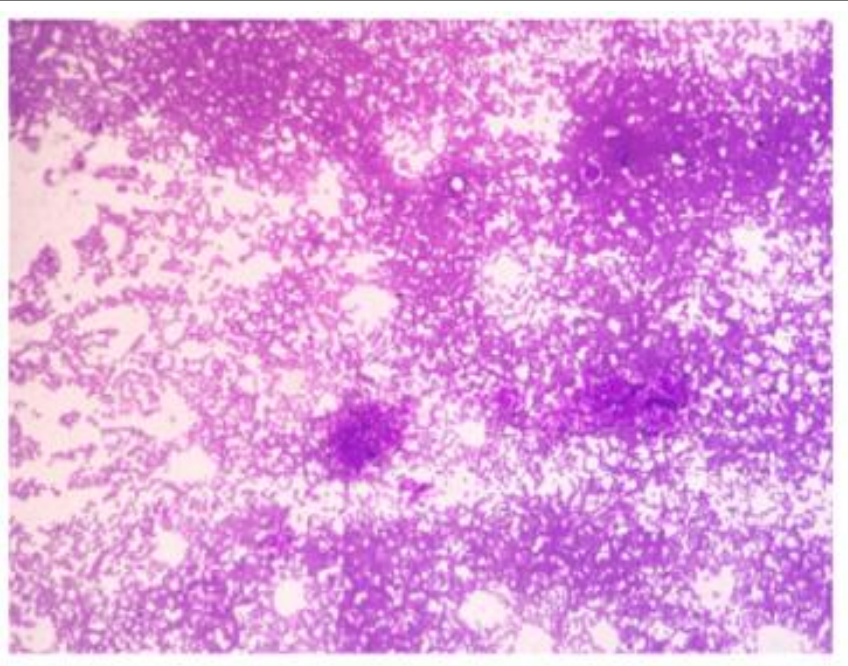

Figure 3: Granulomatous Lymphadenitis

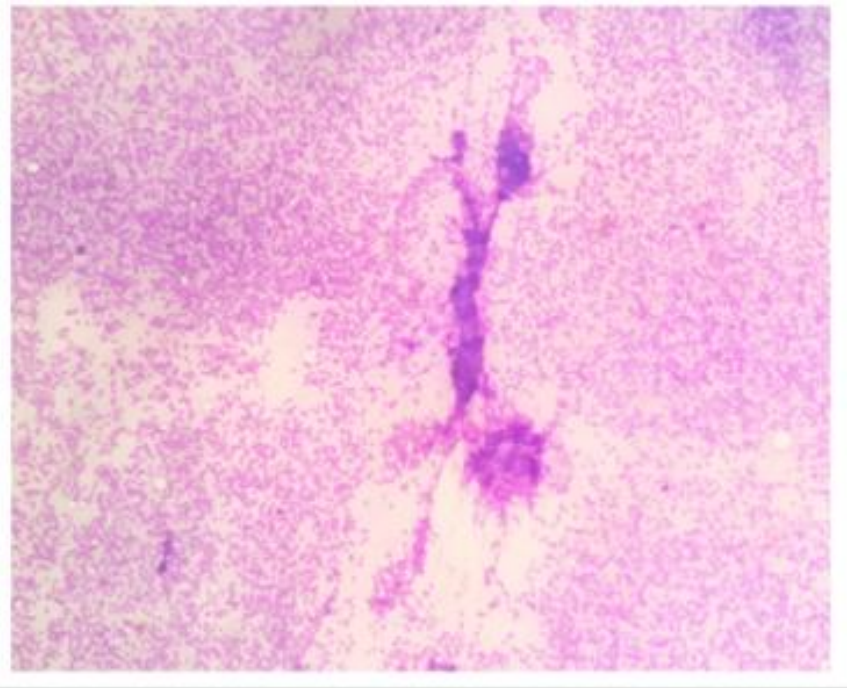

Figure 4: Granulomatous Lymphadenitis

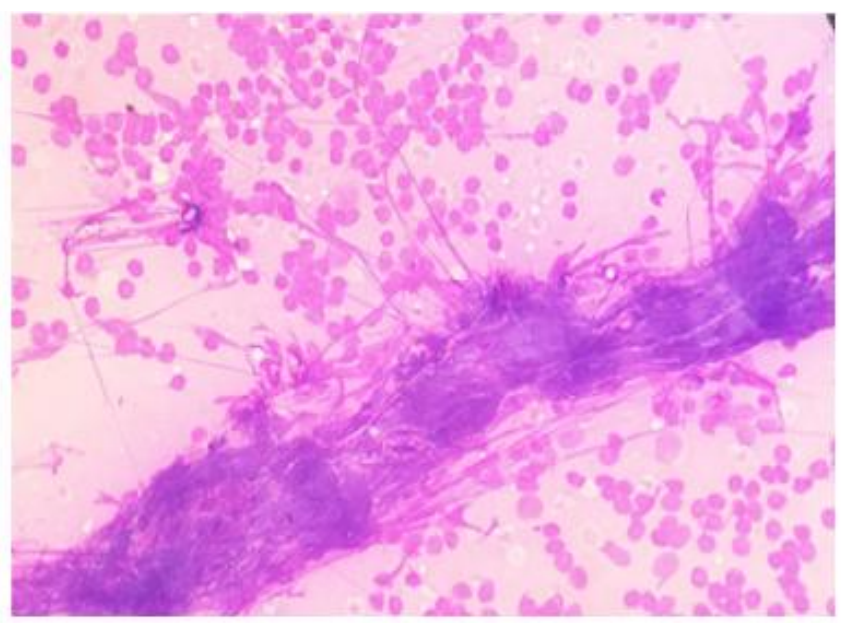

Figure 5: Granulomatous Lymphadenitis

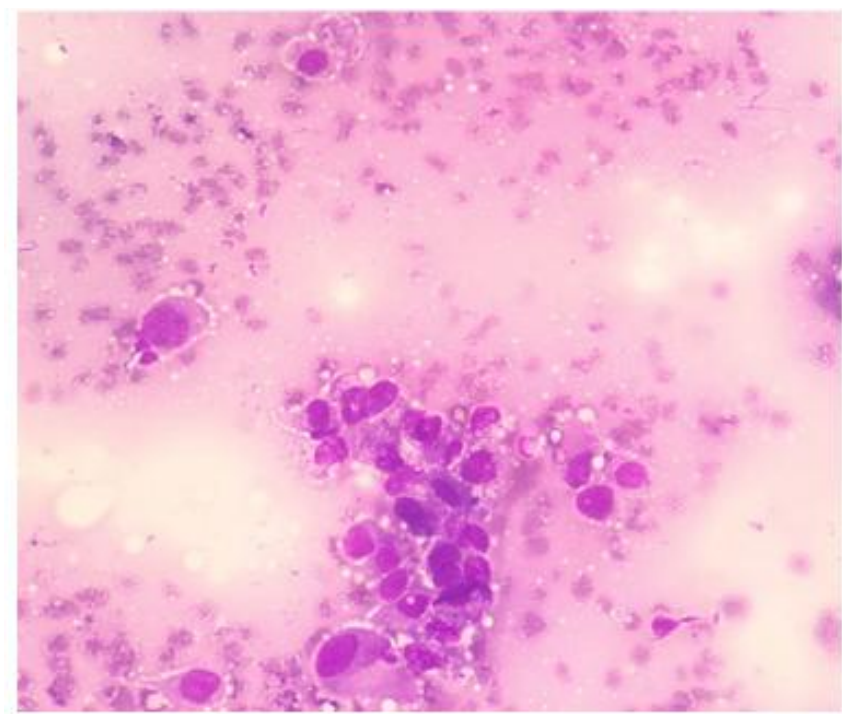

Figure 6: Metastatic deposits in lymph node

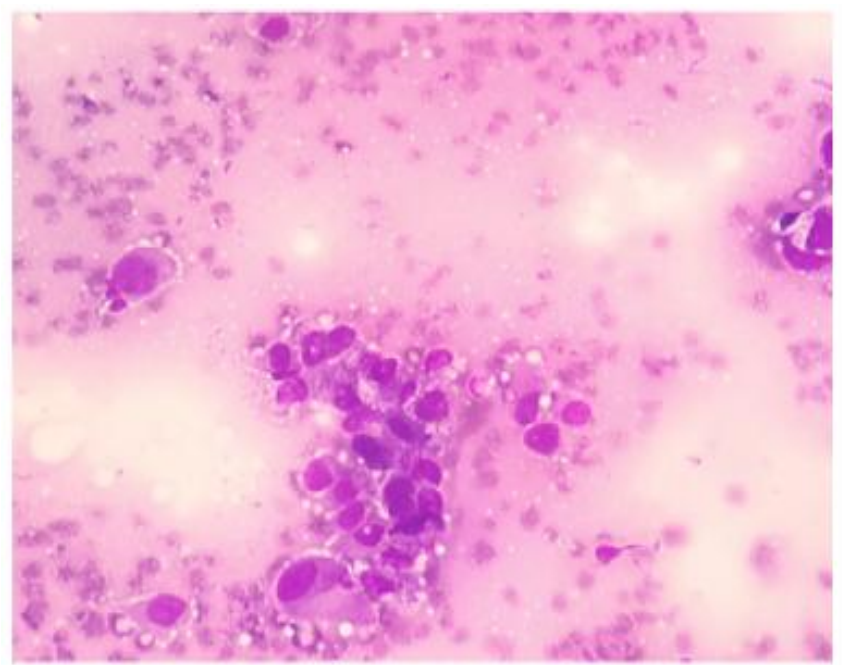

Figure 7: Metastatic deposits in lymph node

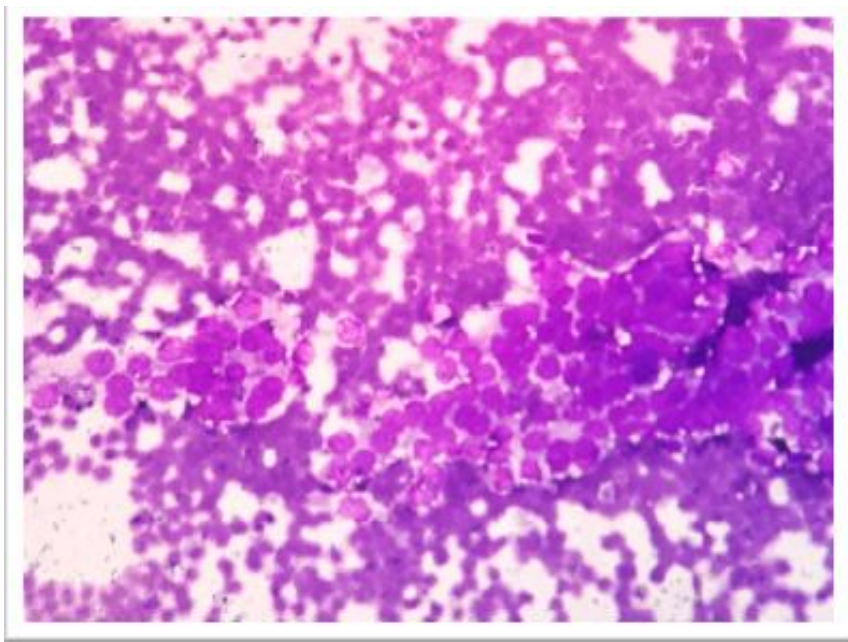

Figure 8: Metastatic deposits in lymph node 


\section{Discussion}

Inflammatory conditions symptomatic or asymptomatic are the major cause of peripheral lymphadenopathy. Although the surgical excision of a peripheral lymph node is fairly easy, however the excision does require anesthesia, sterility and theater and the patient may be left with a scar.

FNAC is a simple, safe, dependable, fast, and less expensive approach of setting up the diagnosis of lesions and enlargements in various parts and organs $^{7-24}$. Lymph node aspiration is of incredible value in diagnosing lymphadenitis, lymphomas, and metastatic carcinoma. The significance of FNAC additionally lies within the early route of appropriate investigations, aside from making the diagnosis. However, obstacles and pitfalls of the procedure are there. In growing nations like India tuberculosis, acute upper respiratory tract infections and suppurative lymphadenitis are some of the common reasons of lymphadenopathy. It has been stated that any lymph node enlargement not subsiding or remaining static in length for greater than 2 weeks after traditional antibiotics need to be thoroughly investigated.

In this evaluation, reactive hyperplasia became the major lesion, however in other studies the major lesion recorded was tuberculosis. The next lesion in the evaluation was metastatic malignancies according to the study undertaken by Malakar et $\mathrm{al}^{8}$.

Further, the study conducted by Annam et al. Recorded an excessive percentage of metastatic malignancies next to reactive hyperplasia ${ }^{17}$. Lymphomas were much less in our evaluation and in accordance with Khajuria's study and Annam et al. study ${ }^{15-17}$. Inadequate aspirates have been much less inside the evaluation carried out by means of Khajuria et al. And Annam et al. Compared to our take a look at and Malakar et al. Did not file any number of inadequate smears

As compared to different studies a moderate male predominance was observed. These findings are comparable with research conducted by way of Gupta et al. And Khajuria et $\mathrm{al}^{3-5}$. In the study undertaken by Reddy et al. Lymph nodes have been studied according to their size and location of presentation and they had concluded that in cervical and axillary location lymph node size of 1 $\mathrm{cm}$ greater than $1.5 \mathrm{cms}$ in the inguinal lymph node and more than $0.5 \mathrm{~cm}$ at any other site are to be taken into important consideration ${ }^{18}$. Although the lymph node lesions were considered consistent with size inside the contemporary study no huge end could be made on the size and location of presentation of lymphadenopathy. In reality many of the total instances majority of them had been ranging in 1-2 cm length, followed by more than 2 $\mathrm{cm}$ with maximum of the instances providing within the cervical area observed by different sites. This can be attributed to the rich lymphatic supply within the neck location the findings are akin to the alternative studies $3,5,8,10,11$.

In this evaluation, majority of the cases recorded have been those of reactive hyperplasia (33.69\%) among which most of them were from the cervical lymph nodes. Reactive hyperplasia is major non specific cause of lymphadenopathy due to a various etiology starting from bacterial, viral or nonspecific etiology. The reactive process is variable, depending on the quantity of stimulation, the number and size of the germinal middle and whether the pattern acquired is from a germinal center or from the interfollicular or paracortical tissue.

The germinal center is represented by poorly defined tissue fragments of poorly cohesive cells. The fragments include centroblast, centrocyte, "tingible body" macrophages, lymphogranular bodies and number of lymphocytes which adhere to the cytoplasm of dendritic retinaculum cells. Smears from interfollicular area consist particularly of lymphocytes, variable number of scattered immunoblasts, plasma cells, non-unique histiocytes and endothelial cell ${ }^{7}$.At times, a part of a lymph node was observed by pathology and as FNA samples most effective a focal area, it can result in false negative results because of sampling mistakes. These findings are in accordance with the studies carried out by way of Narang et al., Janardhan et al. And Khajuria et $\mathrm{a}^{5,13,14}$. 
In dermatopathic lymphadenopathy several non cohesive, faded, histiocytes like cells (interdigitating cells) are present. Pigment containing, macrophages are also observed. These have smaller and extra consistently oval, non folded nuclei extraordinary from interdigitating cells and have a better described cytoplasm. There may be a variable variety of eosinophils. The historical past is predominantly made from lymphocytes which can also seem slightly "strange" with small pale primary nucleoli and blasts are much less common ${ }^{7}$. These findings are in accordance with the other studies ${ }^{20}$.

Tuberculous lymphadenitis normally is the major cause of extra pulmonary tuberculosis and arises as a result of lymphatic spread from a primary focus. Most regularly it involves the cervical lymph nodes attributed to the rich lymphatic drainage of the area and most commonly seen in second and third decades ${ }^{21}$. Tuberculosis, in all age groups, effects within the transmission of the disease in the population. Hence, the diagnosis of this disease with the aid of least intervention method helps in detection and treating the disease. The cytomorphological pattern in tuberculosis is varied and may be divided into 3 patterns. Epithelioid granuloma without necrosis: In India, Mycobacterium tuberculosis infection is most common compared to different granulomatous diseases subsequently the presence of granulomas is particularly suggestive of tuberculosis.

The accessibility of the enlarged lymph nodes for palpation and puncture, the rich cellularity of the smear due to the excessive yield of the aspirate and the ease with which the tumor cells can be differentiated from lymphocytes makes the method of FNA very beneficial in research of metastatic lymphadenitis.

The sample of metastatic deposits of squamous cell carcinoma, accompanied by adenocarcinomas and others are in accordance with different studies $^{3,4,14,16}$. cytological functions of squamous cell carcinoma range depending at the range of differentiation of neoplasm and the degenerated changes. In properly-differentiated squamous cell carcinoma, the neoplastic cells may also have a near resemblance to squamous cells and can create confusion with bronchogenic cysts or epidermal inclusion cysts. Tumor cells in metastatic

adenocarcinomas revealed certain patterns: Monolayer sheets, papillary formation and micro acinar formation. Metastatic deposits of malignant melanoma show marked variant in their cytomorphology. In this evaluation, two instances (6.06\%) were mentioned. The metastatic deposits of breast carcinoma specifically exhibited monolayer sheets of dispersed cells, with poor glandular differentiation. A case of small cell carcinoma of the lung displaying secondaries in the supraclavicular lymph node was observed. The smears showed closely packed cells with scanty cytoplasm, vague small nucleoli, and prominent nuclear molding. The utility of FNAC within the diagnosis of lymphoma is still controversial, specifically in cases of low-grade NHL.

The evaluation conducted with the aid of Narang et al. Recorded a diagnostic accuracy of $88.8 \%$ in co-ordinance with different research ${ }^{13}$.In this evaluation, a complete of 5 cases $(2.6 \%)$ of lymphoma had been recognized out of which four patients $(2.14 \%)$ of NHL and one case $(0.5 \%)$ of Hodgkin's lymphoma. The Cytodiagnosis of NHL relies upon particularly on locating a monomorphic population of lymphoid cells, while its differentiation or grading is predicted by way of cell size and form, presence of nucleoli and mitotic figures. FNAC plays an extra role within the control of Hodgkin's disease in comparison to NHL because it enables in the primary analysis, staging of the affected person and monitoring the recurrence of the disease. Suboptimal cytologic preparations, variable sample in a single node, distinction from reactive lymph node and barriers of the FNAC technique like aspirates can only be taken from the focal area inside the lymph node are some of the shortcomings which make the diagnosis of NHL hard. With the assist of flow cytometry and immunohistochemistry in adjunct to FNAC the prognosis of NHL may be made plenty simpler. Although few instances of NHL 
can be tried to diagnose as in excessive-grade lymphoma-like small non cleaved lymphoma, lymphoblastic lymphoma, immunoblastic lymphoma, myeloblastic, and diffuse big cellular lymphoma as studied with the aid of Hemlatha et $\mathrm{al}^{22}$.

\section{Conclusion}

FNAC has been once more proved as an inexpensive and reliable diagnostic tool. It is ideal for the clinical set up in developing countries for the primary line of research for lymphadenopathy. In the evaluation, reactive hyperplasia turned into recorded as the major cause of lymphadenopathy in the cervical area. Granulomatous lesions had been subsequent in which epithelioid granulomas were seen. The associated case details together ought to be considered as conclusive of tuberculosis.

FNAC used in diagnosing neoplastic and metastatic lesions. It confirms the presence of metastatic deposit but also, in maximum cases, gives the clue regarding the starting place of the primary tumor.

\section{Financial Support and Sponsorship: Nil.}

Conflicts of Interest: There are no conflicts of interest.

\section{References}

1. Slap GB, Brooks JS, Schwartz JS. When to perform biopsies of enlarged peripheral lymph nodes in young patients. JAMA 1984;252:1321-6.

2. Behm FG, O'Dowd GJ, Frable WJ. Fineneedle aspiration effects on benign lymph node histology. Am J ClinPathol 1984;82:195-8.

3. Gupta AK, Nayar M, Chandra M. Reliability and limitations of fine needle aspiration cytology of lymphadenopathies. An analysis of 1,261 cases. ActaCytol 1991;35:777-83.

4. Steel BL, Schwartz MR, Ramzy I. Fine needle aspiration biopsy in the diagnosis of lymphadenopathy in 1,103 patients. Role, limitations and analysis of diagnostic pitfalls. ActaCytol 1995;39:76-81.

5. Khajuria R, Goswami KC, Singh K, Dubey VK. Pattern of lymphadenopathy on FNAC in Jammu. JK Sci 2006;8:157-9.

6. Bibbo M. Lymph Nodes, Comprehensive Cytopathology. 2nd ed. USA: W.B. Saunders Company; 1996. p. 703-29.

7. Orell SR, Sterrett GF, Whitaker D. Lymph Nodes, Fine Needle Aspiration Cytology. 4th ed. India: Churchill Livingstone, Elsevier; 1999. p. 83-124.

8. Malakar D, Jajoo IL, Swarup K, Gupta OP, Jain AP, Poflee VW. A clinical evaluation of fine needle aspiration cytology in the diagnosis of lymphadenopathy. Indian J Tuberc 1991;38:17-9.

9. Rajwanshi A, Bhambhani S, Das DK. Fine-needle aspiration cytology diagnosis of tuberculosis. DiagnCytopathol 1987;3:13-6.

10. Metre MS, Jayaram G. Acid-fast bacilli in aspiration smears from tuberculous lymph nodes. An analysis of 255 cases. ActaCytol 1987;31:17-9.

11. Bailey TM, Akhtar M, Ali MA. Fine needle aspiration biopsy in the diagnosis of tuberculosis. ActaCytol 1985;29:732-6.

12. Das DK. Cytomorphological, Cytochemical and Immunological Characterization of Lymphomas. Doctoral Thesis, Post Graduate Institute of Medical Education and Research, Chandigarh, India;1983.

13. Narang RK, Pradhan S, Singh RP, Chaturvedi S. Place of fine needle aspiration cytology in the diagnosis of lymphadenopathy. Indian $\mathbf{J}$ Tuberc 1990;37:29-31.

14. Bhatt JV, Shah JM, Shah F. Clinicopathological profile of cervical lymphadenopathy. Internet J Pathol 2008;6:(2).

15. Verenkar MP, Kavita K, Pinto WM, Rodrigues S, Pinto RG. Mycobacterial study of fine needle aspirates in cervical 
lymphadenitis. Indian J Tuberc 1996;43: 187-9.

16. Bhagwan IN, Kane SV, Chinoy RF. Cytologic evaluation of the enlarged neck node: FNAC utility in metastatic neck disease. Internet J Pathol 2007;6:(2).

17. Annam V, Kulkarni MH, Puranik RB. Clinicopathologic profile of significant cervical lymphadenopathy in children aged 1-12 years. ActaCytol 2009;53:174-8.

18. Reddy MP, Moorchung N, Chaudhary A. Clinico-pathological profile of pediatric lymphadenopathy. Indian J Pediatr 2002;69:1047-51.

19. Das DK, Pant JN, Chachra KL, Murthy NS, Satyanarayan L, Thankamma TC, et al. Tuberculous lymphadenitis: Correlation of cellular components and necrosis in lymph-node aspirate with A.F.B. positivity and bacillary count. Indian J PatholMicrobiol 1990;33:1-10.

20. Vigliar E, Cozzolino I, Picardi M, Peluso AL, Fernandez LV, Vetrani A, et al. Lymph node fine needle cytology in the staging and follow-up of cutaneous lymphomas. BMC Cancer 2014;14:8.

21. Kochhar AK, Patel KB, Shah M. Pattern of lymphadenopathy on fine needle aspiration cytology of superficial lymph nodes (A study of 150 cases). J Adv Res BiolSci 2012;4:288-92.

22. Hemlatha A, Udaya Kumar M, Harendra Kumar ML. Fine needle aspiration cytology of lymph nodes: A mirror in the diagnosis of spectrum of lymph node lesons. J Clin Biomed Sci 2011;1:164-72.

23. Patel MM, Italiya SL, Dhandha ZB, Dudhat RB, Kaptan KR, Shah MB, et al. Study of metastasis in lymph node by fine needle aspiration cytology: Our institutional experience. Int J Res Med Sci 2013;1:451-4.
24. Finfer M, Perchick A, Burstein DE. Fine needle aspiration biopsy diagnosis of tuberculous lymphadenitis in patients with and without the acquired immune deficiency syndrome. Acta Cytol 1991;35:325-32. 